\title{
Dielectric strength and Volume Resistivity Characteristics of EPR/PVC blends for High Voltage Insulators under Different Environment Conditions
}

\author{
Loai Nasrat \\ Department of Electrical Engineering, \\ Faculty of Engineering, Aswan University, \\ 81542 Aswan, Egypt \\ loaisaad@yahoo.com
}

\author{
Safaa Abdo Ibrahim \\ Elect. Design Department, Alruwwad Co, Aswan \\ Aswan, Egypt \\ abdulrhman1812@yahoo.com
}

\begin{abstract}
In this paper, a new five blends samples containing two different polymeric material Ethylene Propylene Rubber (EPR) and Poly Vinyl Chloride (PVC) with different concentration is prepared. The electrical properties of the blends such as dielectric strength and volume is tested. All experiments are performed under three different condition under dry, wet and acidic environment conditions at atmospheric temperature. They are performed ten times on every samples of the five samples and the average is taken to minimize the error for ensuring the results and reach the optimum blend sample with the optimum electrical property. The dielectric strength test has been done in High Voltage Laboratory using single phase autotransformer. The volume resistivity is measured using Disc electrodes and Electrical tester. The results show improvement for the dielectric strength with increasing the PVC content in the blends samples. Both wet and acidic condition have negative effect on the dielectric strength resulting reduction for the dielectric strength value.
\end{abstract}

Keywords-polymers; EPR/PVC blend; Dielectric strength; Volume resistivity

\section{INTRODUCTION}

With growing demand for electric power, energy voltages also move increasingly. Due to increasing electrical energy trading between countries, we became need to transmits bulk power over large distances with efficiently, and that we are heading to development of our high voltage-cable systems including cables for use in underground and submarine crossing and for urban areas, and that we need to more compact and larger-capacity cables, and the insulation material's properties like insulation strength, heat resistance and mechanical strength must be improved and develop dramatically. And that we are heading to use of polymeric insulators in high voltage cables. [1]-[8]

The word polymers consist of two syllables the first is (poly) mean numerous and the second (mers) mean units or bilateral molecules, polymer is composed of very large number of molecules, Polymer is a general term used primarily to describe a long molecule. This long molecule consists of building blocks of repeated units tied together by chemical bonds. The process of converting these units to the polymer is called polymerization. These modules are made up of monomers, which are often small molecules with low molecule weight.[9]

Polymers are chemical compounds characterized by the chain length but the length of the string that causes the large molecular weight of the compound resulting from repeating units in similar same order along the chain, and therefore called composite polymer and may be the basic constituent unit is composed of a polymer of one or more material and so-called recurring polymer unit in the name of Monomer.[9]

Any electrical cable consist of three essential parts :(1) low resistance conductor for transmitting electrical power, (2)the insulation which from polymer to insulate the conductor from direct contact with earth or other objects and from each other, (3)external protection(sheath or jacket ) against mechanical damage, electrochemical and chemical attack or any e external dangerous to cables. In high voltage polymeric insulated cables others major components should include semiconducive layers that have major roles as we will mention next ,metal screen, water blocking tape, an d reinforcing metal wire.[2]

Polymeric cables are frequently used as a result of high reliability, low maintenance and environmental impact of extruded insulation, reduced cost with respect to paper-oil cables.[3]

The cable Called as the material insulation name used which indicates the importance of insulation in the cable industry, a major cable components Because of this importance, it must be available in the insulation material some specifications taking into account that it is difficult availability of all the specifications and characteristics of good insulation in one insulation material.

Insulation is one of the most important parts of the cable which its thickness proportional with the operating voltage any higher in the voltage increased insulation thickness.

The requirements that must be met in insulation material:

- Higher dielectric strength.

- Long and default service life.

-Higher heat resistance.

- Mechanical flexibility.

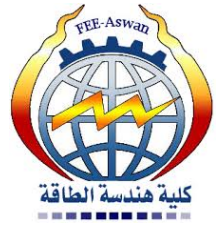




\section{-Resistance to moisture.[10]}

The insulation type depends on operating voltage, temperature surrounding the cable, and type and degree of cable sheath protection.

Ethylene Propylene Rubber EPR is the most important rubber insulators. it is known for its electrical and thermal properties, it is commonly used in high voltage cable and its advantages are their heat, oxidation, weathering, water, acid, polar solvents, Corona, Water-tree, alcohol and alkali resistance, its flexibility make it appropriate using in the mining industry. EPR can be used in the temperature range of $-50^{\circ} \mathrm{C}$ to $160^{\circ} \mathrm{C}$. But $\mathrm{EPR}$ is not as tear resistant as other insulation options. It is also relatively soft and may require more care during installation to avoid damage. EPR used in many electrical applications like power cables, flexible cords, control and instrument wire, automotive ignition wire, mining cable, motor lead wire, molded electrical accessories.[4]-[5]

Polyvinyl chloride (PVC) is a polymeric material that is used extensively in the field of electrical insulation due to its multiple advantages like as the thermal, mechanical and dielectric properties of PVC is excellent also tensile strength and modulus of elasticity is high, so PVC used for power cables insulation. PVC is stronger and more rigid when compared with other general-purpose thermoplastic materials.[6]-[7]

This paper aims to improve Ethylene Propylene Rubber (EPR) / Polyvinyl chloride (PVC) blends electrical properties(dielectric strength, volume resistivity) by adding PVC to EPR in different percentage.it concentrates on finding the best and an appropriate weight percentage of EPR/PVC blend for improving dielectric strength and volume resistivity.

\section{EXPERIMENTAL AND PROCEDURES}

\section{A. Materials used and preparation method}

The chemical components of the materials used in this investigation are as follows:

1. Ethylene Propylene Rubber (EPR) It is the most important rubber insulators. it is known for its electrical and thermal properties, it is commonly used in high voltage cable and its advantages are their heat, oxidation, weathering, water, acid, alcohol, and alkali resistance, its flexibility makes it appropriate using in the mining industry. EPR was supplied by EGYPT AFRICA S.A.E.

2. Polyvinyl chloride(PVC) it is a polymeric material that is used extensively in the field of electrical insulation due to its multiple advantages like as the thermal, mechanical and dielectric properties of PVC is excellent also tensile strength and modulus of elasticity is high, so PVC used for power cables insulation. PVC was supplied by EGY Gates International trading S.A.E.

Five samples taken the shape of disc with $5 \mathrm{~cm}$ diameter and $1 \mathrm{~mm}$ thickness.

\section{B. Samples preparation}

Five blend samples have been prepared by National Research Centre (NRC). The blend was prepared to composition the EPR/PVC blends by mixing or blending both EPR and PVC with different weight percentages concentration as follows: (100/0), (7o / 30), (50/50), (30/70) and $(0 / 100) \%$. Blending process were done in a laboratory at room temperature. The samples were cut and prepared in dimensions suitable for each test technique according to ASTM. table (1) show the mixing formulation of the blend.

TABLE (1).MIXING FORMULATION

\begin{tabular}{|c|c|c|}
\hline samples & EPR Content wt.\% & PVC Content wt.\% \\
\hline 1 & $100 \%$ & 0 \\
\hline 2 & $70 \%$ & $30 \%$ \\
\hline 3 & $50 \%$ & $50 \%$ \\
\hline 4 & $30 \%$ & $70 \%$ \\
\hline 5 & 0 & $100 \%$ \\
\hline
\end{tabular}

\section{Testing Apparatus}

dielectric strength test power supplied from single phase high voltage auto transformer (Terco type HV 9105) 100KV$5 \mathrm{KVA}-50 \mathrm{~Hz}$, the primary of the autotransformer connected to the control desk which supply it and control the output voltage by a $(0-250 \mathrm{~V})$ variac. A $1 \mathrm{M} \Omega$ resistor used to protect the high voltage autotransformer from the high current flow during the test and connected to its secondary. the high voltage set-up enclosed in by an earthen cage.

\section{D. dielectric strength test}

Dielectric strength is one of the most important electrical characteristics that must be taken into account when designing any cable and it defined as the ability of a material to withstand electrical breakdown when a voltage is applied. It usually depends on the thickness of the material and on the method and conditions of the test. to calculate the dielectric strength the samples be placed between two electrode and applying a voltage across these two electrodes and increasing the voltage until break down occur. The test is conducted in air, water (to express the water absorption), oil, solution (to express contamination ) or acid. it is expressed in D :

$$
D=\frac{V}{t}
$$

Where $\mathrm{V}$ is the voltage where break down occur and the thickness of the sample. It can be expressed in terms of voltage gradient like voltage per thickness $(\mathrm{kV} / \mathrm{mm})$. the higher the dielectric strength of a material the better an electrical insulator it makes. Dielectric strength can be tested according to standards such as ASTM D149 or IEC 60243. Fig (1) Schematic diagram used for dielectric strength test. 
International Journal of Applied Energy Systems, Vol. 2, No. 1, Jan 2020 ISSN: 2636 - 3712 (Printed Version) ISSN: 2636 - 3720 (Online Version) Special Issue: ICEE-2019

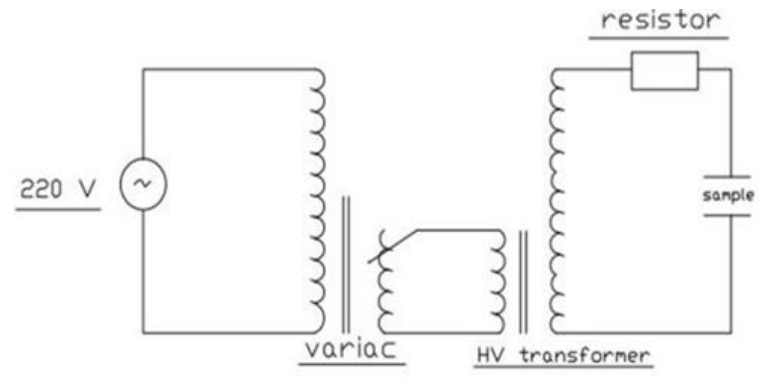

Fig (1): Schematic diagram used for dielectric strength test.

\section{A. Volume resistivity test}

The surface resistivity is known as the electrical resistance of the surface of an insulator material or Surface resistivity is the resistance to current leakage along the surface of an insulator. In the volume resistivity measured by placed the sample one by one between two-disc electrodes have the same diameter applying known voltage to the sample then used resistance tester (high voltage insulators tester) for testing the sample resistance finally the volume resistivity can be calculated from the rule:

$$
\rho=R * \frac{A}{\mathrm{l}}
$$

Where $\rho$ : the volume resistivity, R: the measured resistance, A: Cross section area of the disc sample and $l$ : the thickness of the disc sample.

Volume resistivity dependent on Cross section area, the thickness and also the resistance of the samples. Fig (2) show Schematic diagram of resistivity test arrangement for disc insulator.

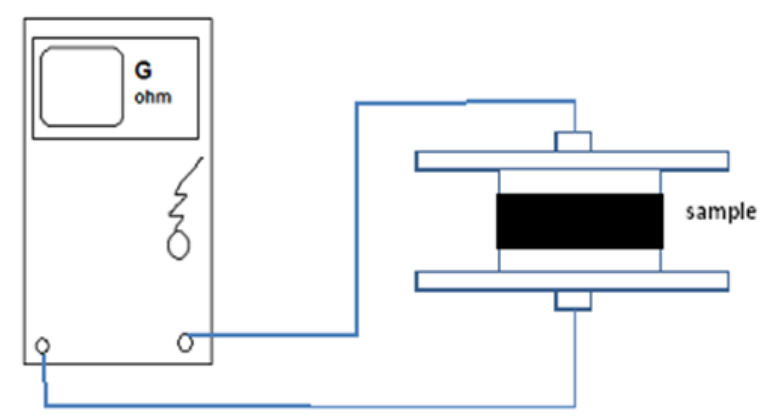

Fig (2) Schematic diagram of resistivity test arrangement for disc insulator

\section{RESULTS AND DISSCUSION}

All tested performed on five EPR/PVC blend samples with different content as follow:
$100 \%$ EPR with $0 \%$ PVC, $70 \%$ EPR with $30 \%$ PVC, $50 \%$ EPR with 50\% PVC, 30\% EPR with 70\% PVC and 0\% EPR with $100 \%$ PVC under different condition (dry, wet, sulfuric acid $\mathrm{H} 2 \mathrm{SO} 4$ ) condition at atmospheric temperature.

\section{A. Results of dielectric strength test}

The dielectric strength for all EPR/ PVC blends samples mentioned above was investigated under different conditions the data obtained and plotted in flow chart as shown in Fig (3) which show Dielectric strength $\mathrm{KV} / \mathrm{mm}$ for EPR/PVC blend samples under different conditions.

Under wet condition the percentage of dielectric losses take place in (100/0) \% EPR/PVC blend sample was $14.89 \%$ as the dielectric strength reduced from $18.59 \mathrm{KV} / \mathrm{mm}$ under dry environment condition to $16.18 \mathrm{KV} / \mathrm{mm}$ under wet environment condition.

Under acid condition the percentage of dielectric losses take place in (100/0) \% EPR/PVC blend sample was $30.18 \%$ as the dielectric strength reduced from $18.59 \mathrm{KV} / \mathrm{mm}$ under dry environment condition to $14.28 \mathrm{KV} / \mathrm{mm}$ under acidic environment condition.

Under wet condition the percentage of dielectric losses take place in (70/30) \% EPR/PVC blend sample was $8.99 \%$ as the dielectric strength reduced from $20.98 \mathrm{KV} / \mathrm{mm}$ under dry environment condition to $19.25 \mathrm{KV} / \mathrm{mm}$ under wet environment condition.

Under acid condition the percentage of dielectric losses take place in (70/30)\% EPR/PVC blend sample was $15.40 \%$ as the dielectric strength reduced from $20.98 \mathrm{KV} / \mathrm{mm}$ under dry environment condition to $18.18 \mathrm{KV} / \mathrm{mm}$ under acid environment condition.

Under wet condition the percentage of dielectric losses take place in (50/50) EPR/PVC blend sample was $15.13 \%$ as the dielectric strength reduced from $22.91 \mathrm{KV} / \mathrm{mm}$ under dry environment condition to $19.90 \mathrm{KV} / \mathrm{mm}$ under wet environment condition.

Under acid condition the percentage of dielectric losses take place in (50/50)\% EPR/PVC blend sample was $18.09 \%$ as the dielectric strength reduced from $22.91 \mathrm{KV} / \mathrm{mm}$ under dry environment condition to $19.40 \mathrm{KV} / \mathrm{mm}$ under acid environment condition.

Under wet condition the percentage of dielectric losses take place in (30/70)\% EPR/PVC blend sample was $15.32 \%$ as the dielectric strength reduced from $25.37 \mathrm{KV} / \mathrm{mm}$ under dry environment condition to $22 \mathrm{KV} / \mathrm{mm}$ under wet environment condition.

Under acid condition the percentage of dielectric losses take place in (30/70)\% EPR/PVC blend sample was $18 \%$ as the dielectric strength reduced from $25.37 \mathrm{KV} / \mathrm{mm}$ under dry environment condition to $21.50 \mathrm{KV} / \mathrm{mm}$ under acid environment condition.

Under wet condition the percentage of dielectric losses take place in (0/100) \% EPR/PVC blend sample was $8.92 \%$ as the 
dielectric strength reduced from $27.12 \mathrm{KV} / \mathrm{mm}$ under dry environment condition to $24.90 \mathrm{KV} / \mathrm{mm}$ under wet environment condition.

Under acid condition the percentage of dielectric losses take place in $(0 / 100) \%$ EPR/PVC blend sample was $18.74 \%$ as the dielectric strength reduced from $27.12 \mathrm{KV} / \mathrm{mm}$ under dry environment condition to $22.84 \mathrm{KV} / \mathrm{mm}$ under acid environment condition.

Presence water and acid in samples environment or wet and acid conditions has negative effect on dielectric strength of insulation material samples that due to degradation of blend samples resulted from water and acid absorption which lead to decreasing the dielectric strength of the samples.

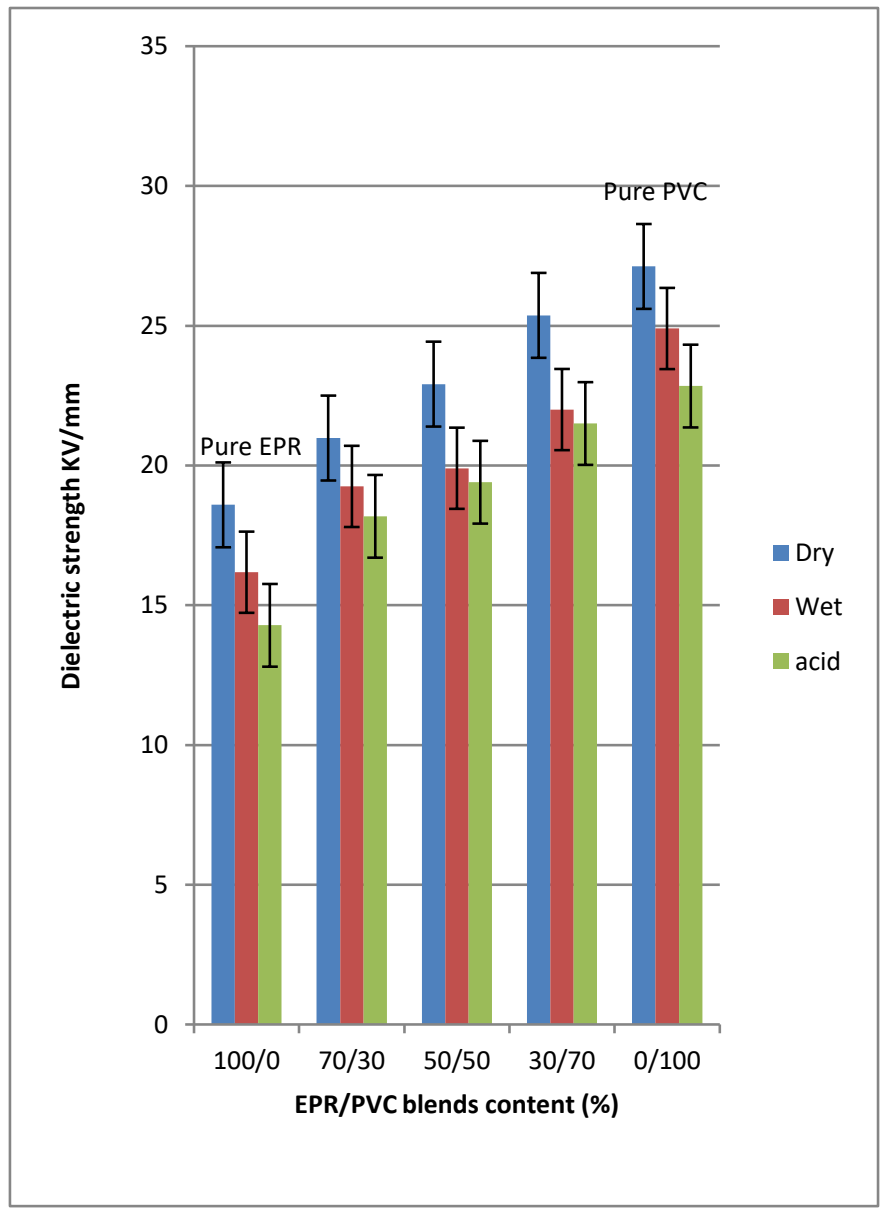

Fig(3) Dielectric strength $\mathrm{KV} / \mathrm{mm}$ for EPR/PVC blends samples under different conditions
Fig (4) showed that under wet environment condition (70/30)\% EPR/PVC blend advantages by lower dielectric losses than pure EPR but higher than pure PVC, the value of dielectric losses increased with increasing PVC content in the blend under wet condition. Increasing PVC content in EPR/PVC blend improved the electrical properties(dielectric strength) but for PVC content above $30 \%$ lead to increasing the ability of blend to water absorption, but under acidic environment condition and at pure EPR percentage of dielectric losses was $30.18 \%$ this value decreased to $15.40 \%$ when blended $70 \%$ EPR with $30 \%$ PVC then it begun increasing to be $18.09 \%$ at $50 \% \mathrm{PVC}$ and $50 \% \mathrm{EPR}$ and then reduced by small amount to be $18 \%$ with increasing PVC content (70\%PVC with $30 \%$ EPR) and finally increased again to be $18.74 \%$ at $100 \%$ PVC or pure PVC. Blending PVC with EPR resulted in decreasing the ability of blend sample to degradation which resulted from acid absorption at 30\% PVC and the best blend sample in view of this principle is (70/30)\% EPR/PVC blend sample but when the content of PVC increased at $50 \%$ PVC the ability for acid absorption increased as compared with 30\% PVC blend sample.

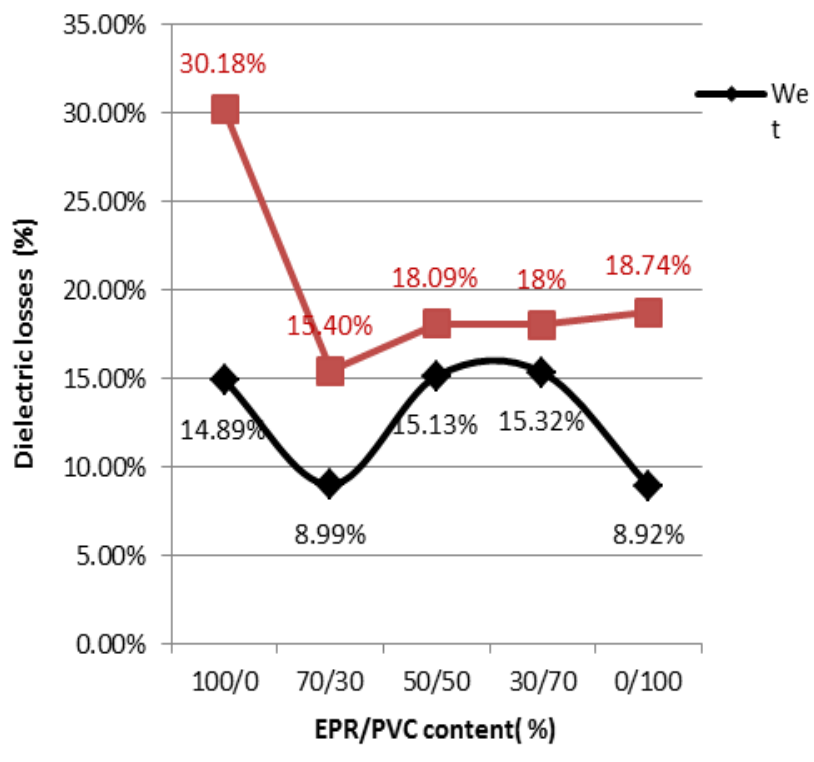

Fig(4) the percentage of dielectric losses under wet and acid conditions

\section{B. volume resistivity test}

The volume resistivity for all EPR/PVC blends samples mentioned above was studied under different conditions the data obtained and plotted in flow chart as shown in Fig (6) which show volume resistivity for EPR/PVC blends sample under different conditions.

For pure EPR sample under wet condition the percentage of losses in the volume resistivity was $26.80 \%$ as it reduced from $1050.9 \Omega . c m$ under dry environment condition to 828.78 $\Omega . c m$ under wet environment condition. 
For pure EPR sample under acid environment condition the percentage of losses in the volume resistivity was $14.89 \%$ as the volume resistivity reduced from $1050.9 \Omega$.cm under dry environment condition to $717.9 \Omega$.cm under acid environment condition.

For (70/30)\% EPR /PVC blend sample under wet environment condition the percentage of losses in volume resistivity was $29.85 \%$ as it reduced from $845.6 \Omega$.cm under dry environment condition to $651.20 \Omega . \mathrm{cm}$ under wet environment condition.

For $(70 / 30) \%$ EPR /PVC blend sample under acid environment condition the percentage of losses in volume resistivity was $65.88 \%$ as it reduced from $845.6 \Omega$.cm under dry environment condition to $509.78 \Omega . \mathrm{cm}$ under acid environment condition

For $(50 / 50) \%$ EPR /PVC blend sample under wet condition the percentage of losses in volume resistivity was $62.06 \%$ as it reduced from $376.3 \Omega . \mathrm{cm}$ under dry environment condition to $232.20 \Omega$.cm under wet environment condition.

For $(50 / 50) \%$ EPR /PVC blend sample under wet condition the percentage of losses in volume resistivity was $69.96 \%$ as it reduced from $376.3 \Omega . \mathrm{cm}$ to $221.40 \Omega . \mathrm{cm}$ under wet environment condition.

For (30 / 70)\% EPR /PVC blend sample under wet condition the percentage of losses in volume resistivity was $68.48 \%$ because it reduced from $157.7 \Omega . \mathrm{cm}$ under dry environment condition to $93.60 \Omega$.cm under wet environment condition.

For $(30$ / 70)\% EPR /PVC blend sample under acid condition the percentage of losses in volume resistivity was $85.77 \%$ because it reduced from $157.7 \Omega . \mathrm{cm}$ under dry environment condition to $84.89 \Omega . \mathrm{cm}$ under acid environment condition.

For pure PVC blend sample under wet condition the percentage of losses in volume resistivity was $19.83 \%$ because of reduced from $22.9 \Omega$.cm under dry environment condition to $19.11 \Omega . c m$ under wet condition.

For pure PVC blend sample under acid condition the percentage of losses in volume resistivity was $40.49 \%$ as volume resistivity decreased from $22.9 \Omega . \mathrm{cm}$ under dry environment condition to $16.30 \Omega$.cm under acid condition.

Volume resistivity decreased with increasing PVC content to the blends due to the isolation resistance of Ethylene propylene Rubber (EPR) is higher than (PVC) Polyvinyl Chloride. this is because of the difference in chemical composition of both (EPR )and (PVC) as EPR from polymeric rubber and PVC from plastic polymer and the isolation resistance of rubber are higher than in case of plastic so the volume resistivity decreased with increasing PVC content.

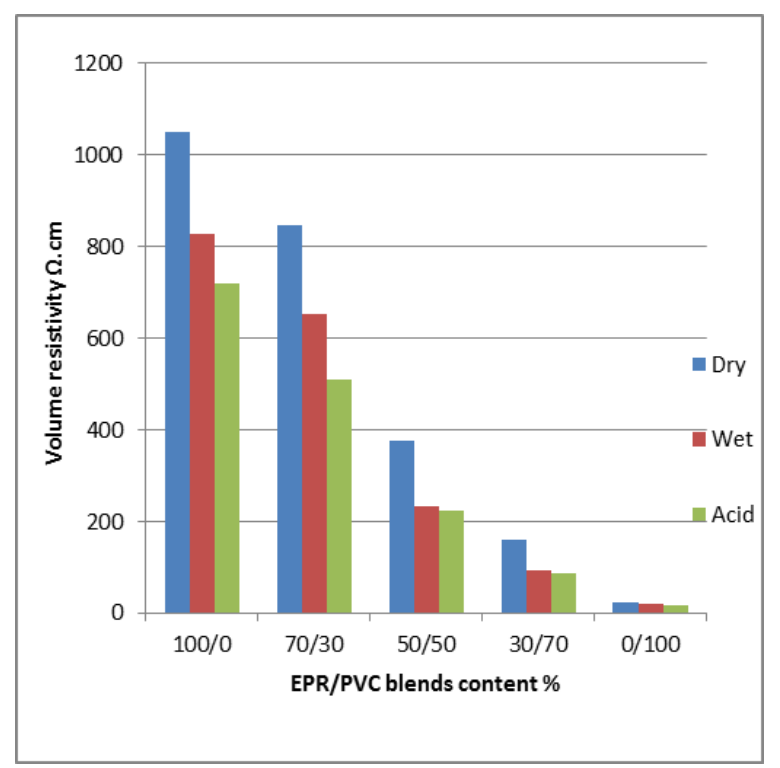

Fig (5)volume resistivity for EPR/PVC blends sample under different conditions

Fig(6) show volume resistivity losses (\%) under wet condition it is noticeable that volume resistivity losses $(\%)$ for pure EPR sample under acidic condition was $26.8 \%$ higher than that for pure PVC sample $19.83 \%$ and when blended PVC content with EPR content the percentage of losses increased to be $(29.85$, $62.06,68.48)$ for $((70 / 300,(50 / 50),(30 / 70))$ blend samples respectively.

Losses percentage in volume resistivity increased with increasing PVC content this can be explained as increasing PVC content increasing the ability of blends samples to water absorption. Also, fig (6) show volume resistivity losses (\%) under acidic condition it is obvious that volume resistivity losses $(\%)$ for pure EPR sample under acidic condition was $14.89 \%$ lower than that for pure PVC sample $40.49 \%$ and when bended PVC content with EPR content the percentage of losses increased became $(65.88,69.96,85.77)$ for $((70 / 300$, (50/50), (30/70)) blend samples respectively.

Losses percentage in volume resistivity increased with increasing PVC content this can be explained as increasing

PVC content increasing the ability of blends samples to acidic absorption. 


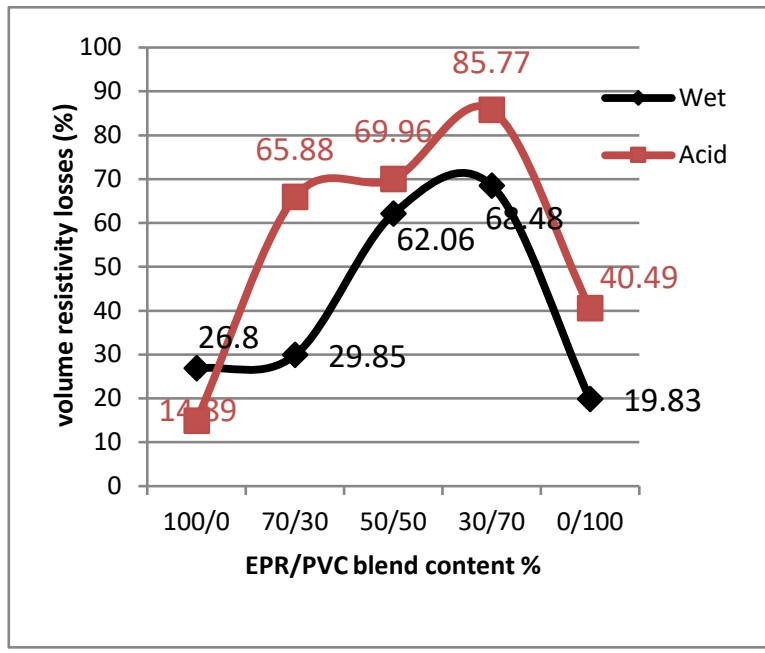

resistivity losses under wet and acidic condition
[1] I. A. Metwally, "High-voltage power cables plug into the future," IEEE Potentials, vol. 27, no. 1, pp. 18-25, 2008.

[2] J. Rohan. Lucas "High voltage engineering", 2001.

[3] W. Thue, Electrical Power Cable Engineering, Second Editions,"CRC Press Inc., Second edition, Chapters 1, 2, 5, 2003.

[4] L.Cao and S. Grzybowski " Accelerated Aging Study on $15 \mathrm{kV}$ XLPE and EPR Cables Insulation Caused by Switching Impulses" IEEE Transactions on Dielectrics and Electrical Insulation Vol. 22, No. 5; October $2015,2809$.

[5] S. Grzybowski, L. Cao and P. Shrestha, "Electrical degradation of $15 \mathrm{kV}$ XLPE and EPR cable energized by switching impulses," 16th Int'l. Sympos. High Voltage Eng. (ISH), Johannesburg, South Africa, CD, Paper A-018, 2009.

[6] A. T. Mohamed" Thermal experimental verification on effects of nanoparticles for enhancing electric and dielectric performance of polyvinyl chloride" Measurement 89 (2016) 28-33.

[7] A. Aman, M.M. Yaacob, M.A. Alsaedi, Kh.A. Ibrahim, Polymeric composite based on waste material for high voltage outdoor application, IJEPES Int. J. Electr. Power Energy Syst. 45 (1) (2013) 346-352.

[8] P. Igic, P. Holland, S. Batcup, R. Lerner, and A. Menz, in IEEE International Symposium on Power Semiconductor Devices and IC's,2006. ISPSD 2006, 2006, pp. 1-4.

[9] R. A. Bernstorf, R. K. Niedermier, D. S. Winkler "Polymer Compounds Used In High Voltage Insulators" Chemical book, EU 1407-HR1.

[10] S. L. Uppal and S. Rao, "Electrical Power Systems", Fifteenth edition, Book, 2005

\section{IV.CONCLUSIONS}

1. The dielectric strength improved with increasing PVC content in the blends. [30\%EPR,70\% PVC] blend sample has the highest dielectric strength of :

- $25.37 \mathrm{KV} / \mathrm{mm}$ (36.47\% improvement) under dry condition.

- $22 \mathrm{KV} / \mathrm{mm}$ (35.97\% improvement) under wet condition.

- $21.50 \mathrm{KV} / \mathrm{mm}$ (18\% improvement ) under acidic condition.

2. Exposure the samples to sulfuric acid $\mathrm{H} 2 \mathrm{SO} 4$ affected negatively on its dielectric strength.

3. Wet condition resulted in decreasing the dielectric strength due to water absorption.

4. Pure EPR sample has the highest value of volume resistivity $1050.9 \Omega . \mathrm{cm}$, but pure PVC sample has lowest volume resistivity value $22.9 \Omega . \mathrm{cm}$.

5. Volume resistivity of the blend sample reduced with increasing PVC content under all three different conditions.

6. Volume resistivity of all samples reduced when exposed to both water and sulfuric acid $\mathrm{H} 2 \mathrm{SO} 4$.

\section{REFERENCES}

